\title{
An Epidemiological Survey of Food Reactions Among Kindergarten Children in Zanjan, Iran
}

\author{
Akefeh Ahmadiafshar ${ }^{1,2,3 *}$ iD , Saeideh Mazloomzadeh ${ }^{1,2}$ iD Zohre Torabi $^{3}$ (D), Kimia Haghighat ${ }^{4}$ iD \\ 1. Social Determinants of Health Research Center, Zanjan University of Medical Sciences, Zanjan, Iran \\ 2. Metabolic Diseases Research Center, Zanjan University of Medical Sciences, Zanjan, Iran \\ 3. Dept. of Pediatrics, Mousavi Hospital, Zanjan University of Medical Sciences, Zanjan, Iran \\ 4. Science and Research Branch, Islamic Azad University, Tehran, Iran
}

Article Info
dol 10.30699/jambs.26.119.6
Received: 2018/04/18;
Accepted: 2018/11/14;
Published Online: 01 Nov 2018;
Use your device to scan and read the
article online
Corresponding Information:
Akefeh Ahmadiafshar, Social Determinants
of Health Research Center, Zanjan
University of Medical Sciences, Zanjan,
Iran
Email: akefeh45@zums.ac.ir

ABSTRACT

Background \& Objective: Food allergy is an important and increasing problem in children. The aim of this study was to investigate the type and prevalence of food reactions in child care centers of Zanjan city (northwest, Iran).

Materials \& Methods: This cross-sectional study was performed in 40 kindergartens from Zanjan city. A questionnaire containing information about the occurrence of food reaction, offending food, type of reaction, feeding and birth history, and atopy in the children and their families, was prepared and completed by the parents. Then, the data were gathered and analyzed by SPSS 16 .

Results: In this study 801 children between the ages of 6 months to 5 years entered the study. Two hundred and one reactions $(25.1 \%)$ were reported. Skin reactions including; urticaria (47.3\%) and dermatitis (8\%) were registered as the most common problems. Cow's milk $(32.3 \%)$ was the most offending food. There was significant correlation between age, duration of breast feeding, personal and family history of atopy, and food reactions; however, we did not find any correlation between birth body weight, gender, time of complementary feeding and food reaction.

Conclusion: This study showed a high prevalence of food reaction in Zanjan city. Therefore, along with confirmatory diagnostic tests, family education for prevention and treatment of children is recommended.

Keywords: Food allergy, Preschool children, Foods

\section{Introduction}

Food reaction is one of the most important health problems (especially in advanced societies). The clinical manifestations may vary from mild to severe, even to life threatening symptoms such as sudden death and severe asthma attacks following the eating of certain foods, have been reported $(1,2)$. Its prevalence was $5-7 \%$ in children younger than 5 years old, and about $3-6 \%$ in the older population (3-5). Cow milk, eggs, wheat, soy beans, sea foods and nuts are common and important causes of food reactions in children $(6,7)$.

The type and rate of food reaction varies among different populations and areas. In Europe and Western countries, cow milk, egg, and peanut allergies are common culprit agents, whilst in Asia and eastern areas; cow milk, chicken and seafood are the more common allergens (3-5). However, these foods are important sources of nutrients. Usually, a reaction to certain foods such as cow's milk and egg might be eliminated by growing up, but reactions to some foods, such as nuts and seafood usually persist $(8,9)$. The reaction to food often occurred with immunologic response. It might also be non-immune mediated reactions that encompass different categories such as disorders in digestion and absorption, inborn metabolism errors, and also pharmacological and toxic reactions (10).

Several types of immune-mediated adverse reactions to foods have been reported including: IgE-mediated, cellmediated, and mixed-mechanism $(\mathbf{8}, \mathbf{1 1}, \mathbf{1 2})$. IgEmediated reactions can manifest as hives, angioedema, facial flushing and papular rashes on the body. In the gastrointestinal tract, they manifest as abdominal pain, itching around the lips, mouth and the throat; in the respiratory tract with symptoms of rhino-conjunctivitis and symptoms of shortness of breath due to bronco spasms, which finally present as anaphylaxis and shock. Some IgE-mediated reactions are accompanied by stimulation of T-lymphocytes, such as atopic dermatitis, esophagitis, eosinophilic gastroenteritis and asthma. Some reactions are non IgE-mediated and stimulated by cellular lymphocytes such as contact dermatitis, herpeti form dermatitis, colitis and enterocolitis due to food proteins and celiac disease $(3,11-13)$. 
The diagnosis of food allergy is possible by taking history and physical examination. It is usually confirmed by skin testing, specific serum IgE assessment and ultimately oral challenge with the suspected food $(1,8,14)$.

Considering the trend of the increasing prevalence of food reaction, especially in children, and its adverse consequences, investigating the occurrence of the reaction and the type of responsible food could be beneficial. In this study, the frequency of food reaction and related factors among kindergarteners in Zanjan city was evaluated.

\section{Materials and Methods}

This cross-sectional study was performed on kindergarteners in Zanjan in 2015. After getting approval and coordinating with the welfare organization of Zanjan, 40 kindergartens were randomly selected and all children under the age of 6 entered the study.

In each center, after explaining the study to the kindergarten teachers and instructing them, the aim of study was described to the parents. The questionnaires were then given to parents, who were asked to fill them. The questionnaires contained information about the age and gender of child, his/her history of food reaction and the type of reaction, the type of offending foods, history of atopy in children and family, parents' occupation, family income, as well as the children's birth and feeding history.

Then, the data was analyzed using SPSS 16.0 (SPSS Inc., Chicago, IL., USA). An odds ratio with a confidence interval of $95 \%$ was used for the measurement of the strength of the relationship between variables.

This study was approved by the ethics committee of Zanjan University of Medical Sciences and its Ethics Code number is ZUMS.REC.1393.140.

\section{Results}

In this study, 1200 questionnaires were distributed among parents of children in daycare centers; 801 parents completed the questionnaire with consent. A total 443 girls (55.3\%) and 358 boys (44.7\%) were evaluated. The age of the children was between 6 months to 6 years with a mean age of $3.84 \pm 1.95$ years.

Reaction to food was reported in 201 children (25.1\%). The most common cause was cow milk and the most frequent involvement was hives and skin rash (Figure 1) (Table 1).

There was significant correlation between age of the children and food reaction (Table 2).

There was no significant correlation between gender, family income, birth weight, history of breast feeding and time of complementary feeding. However, we found a reverse correlation between the duration of breast feeding and food reaction; P-value=0.002, OR: 0.96 (95\% CI: 0.93-0.98) (Table 3).

We found a significant correlation between the personal and family history of atopy and a higher frequency of food reaction among children (Table 3 ).

There was a significantly higher frequency of gastrointestinal (GI) and respiratory involvement with cow milk intake, and we also found that skin and respiratory problems were more common after eating sweets (Table 4).

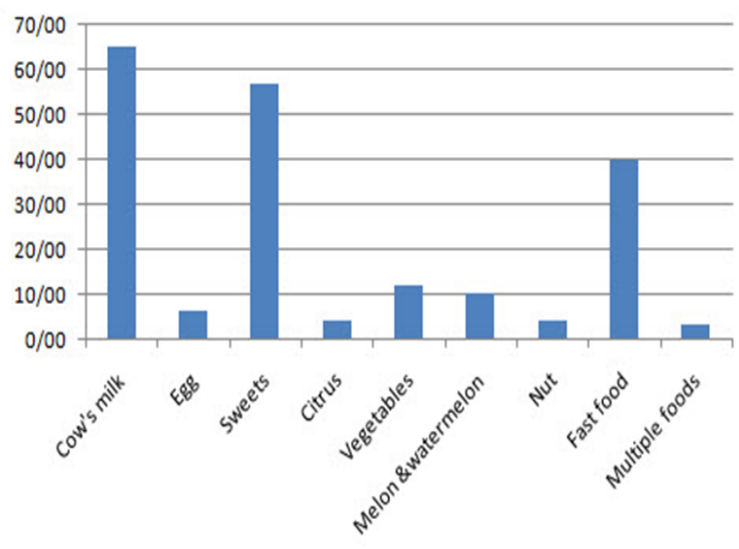

Figure 1. The frequency of reactions with different types of foods

Table 1. The types of food reactions among children

\begin{tabular}{|ccc|}
\hline Reaction & Number & Percent \\
\hline Urticaria & 95 & 47.3 \\
\hline Dermatitis & 16 & 8 \\
\hline Wheezing & 24 & 11.9 \\
\hline Nausea and vomiting & 19 & 9.5 \\
Diarrhea & 20 & 10 \\
\hline Bloody stool & 7 & 3.5 \\
\hline Multiple organs & 18 & 9 \\
\hline Other* & 2 & 1 \\
\hline All & 201 & 100 \\
\hline
\end{tabular}

*including one case with irritability and one case with perianal itching 
Table 2. The frequency of food reaction in different ages of the children

\begin{tabular}{|c|c|c|c|}
\hline Age(year) & Number (\%) & Food reaction (\%) & PV \\
\hline 1 & $21(2.6)$ & $7(3.5)$ & \multirow{6}{*}{0.011} \\
\hline 2 & $60(7.5)$ & $16(8)$ & \\
\hline 3 & $240(30)$ & $78(39)$ & \\
\hline 4 & $184(22.9)$ & $48(23.5)$ & \\
\hline 5 & $296(37)$ & $52(26)$ & \\
\hline Total & $801(100)$ & $201(100)$ & \\
\hline
\end{tabular}

Table 3. The characteristics of children and comparing the children with food reaction and without reaction and odds ratio with $95 \%$ Confidence interval on the basis of characters

\begin{tabular}{|c|c|c|c|c|c|c|}
\hline \multirow[b]{2}{*}{ Characters } & \multirow[b]{2}{*}{ Children } & \multicolumn{2}{|c|}{ Food Reaction } & \multirow[b]{2}{*}{ P-value } & \multirow[b]{2}{*}{ OR } & \multirow[b]{2}{*}{$95 \% \mathrm{CI}$} \\
\hline & & $\begin{array}{c}\text { Yes } \\
\text { n }(\%)\end{array}$ & $\begin{array}{c}\text { No } \\
\mathbf{n}(\%)\end{array}$ & & & \\
\hline \multicolumn{7}{|l|}{ Sex } \\
\hline Male & 439 & $117(58.5)$ & $322(54.2)$ & \multirow{2}{*}{0.29} & 1.00 & - \\
\hline Female & 355 & $83(41.5)$ & $272(45.8)$ & & 0.83 & $0.61-1.16$ \\
\hline \multicolumn{7}{|l|}{ Family income $\dagger$} \\
\hline Low & $127(16.7)$ & $30(15.9)$ & $97(17)$ & \multirow{3}{*}{0.298} & 1.00 & - \\
\hline Moderate & $355(46.7)$ & $81(42.7)$ & $274(48)$ & & 0.96 & $0.59-1.54$ \\
\hline High & $278(36.6)$ & $78(41.2)$ & 200(35) & & 1.26 & $0.78-2.05$ \\
\hline Birth weight (gr) & $3183 \pm 450$ & $3176 \pm 441$ & $3186 \pm 454$ & 0.84 & 1.000 & $1.00-1.00$ \\
\hline \multicolumn{7}{|l|}{ Breast feeding } \\
\hline Yes & 642 & $160(81.6)$ & $492(83.8)$ & \multirow{2}{*}{0.298} & 1.17 & $0.76-1.78$ \\
\hline No & 129 & $37(18.4)$ & $93(16.2)$ & & & \\
\hline Breast feeding duration (months) & $18.47 \pm 6.32$ & $17.07 \pm 6.66$ & $18.95 \pm 1.13$ & $0.002^{*}$ & 0.96 & $0.93-0.98$ \\
\hline Complementary feeding age(months) & $5.9 \pm 1.48$ & $6.07 \pm 1.69$ & $5.96 \pm 1.39$ & 0.376 & 1.05 & $0.94-1.17$ \\
\hline \multicolumn{7}{|l|}{ Atopy } \\
\hline No & $614(77)$ & $70(34.8)$ & $544(91.1)$ & \multirow{2}{*}{$<0.0001 *$} & 19.2 & $12.8-28.8$ \\
\hline Yes & $184(23)$ & $131(65.2)$ & $53(8.9)$ & & & \\
\hline \multicolumn{7}{|l|}{ Atopy in family } \\
\hline No & $706(88.1)$ & $161(80.1)$ & $545(90.8)$ & \multirow{2}{*}{$<0.0001 *$} & 2.46 & $1.58-3.84$ \\
\hline Yes & $95(11.9)$ & $40(19.9)$ & $55(9.2)$ & & & \\
\hline
\end{tabular}

$\uparrow$ Low income: Salary lower than 10000000 Rails/month; Moderate income: salary 10000000> and <20000000Rails/month; High Income: salary more than 30000000Rails/month

Table 4. The frequency of skin, respiratory, Gastro intestinal and multiple organs involvements with different types of foods in children

\begin{tabular}{|c|c|c|c|c|c|c|c|c|c|c|c|}
\hline \multirow{2}{*}{ Food } & \multicolumn{2}{|c|}{ Skin } & \multicolumn{2}{|c|}{ respiratory } & \multicolumn{2}{|c|}{ GI } & \multicolumn{2}{|c|}{ Multiple } & \multicolumn{2}{|c|}{ All } & \multirow[t]{2}{*}{ pv } \\
\hline & $\mathrm{N}$ & $\%$ & $\mathrm{~N}$ & $\%$ & $\mathrm{~N}$ & $\%$ & $\mathrm{~N}$ & $\%$ & No & $\%$ & \\
\hline Cow's milk & 14 & 12.5 & 10 & 41.7 & 31 & 67.4 & 10 & 52.6 & 65 & 32.3 & \\
\hline Egg & 4 & 3.6 & 0 & 0 & 2 & 4.3 & 0 & 0 & 6 & 3 & \\
\hline Sweets & 38 & 33.8 & 8 & 33.3 & 7 & 15.2 & 4 & 21.1 & 57 & 28.4 & \\
\hline Snacks \& appetizers & 37 & 33 & 3 & 12.5 & 1 & 2.2 & 2 & 10.5 & 43 & 21.4 & $<0.0001$ \\
\hline Fruits \& vegetables* & 16 & 14.3 & 2 & 8.3 & 5 & 10.8 & 3 & 15.8 & 26 & 12.9 & \\
\hline Nuts & 3 & 2.7 & 1 & 4.2 & 0 & 0 & 0 & 0 & 4 & 2 & \\
\hline All & 122 & 100 & 24 & 100 & 46 & 100 & 19 & 100 & 201 & 100 & \\
\hline
\end{tabular}

* Fruits and vegetables including; citrus, vegetables, melon and water melon 


\section{Discussion}

Our study showed that about one fourth of children had food reaction that was higher than other epidemiologic studies $(5,8,15,16)$. However, in some studies which were based on parents' reports with no confirmatory assessments such as specific IgE evaluation and skin tests, results, similar to our study, were reported. $(4,7)$ One meta-analysis by Rona et al. demonstrated that the prevalence of self-reported food reactions for any food varied between $3 \%$ to $35 \%$ (17). In another comparative study that was done in Estonia and Sweden, the prevalence of self-reported food allergy was similar in two countries and about twice higher in children with wheezing than in children without wheezing. However, $3 \%$ of the children with perceived food allergy in Estonia, compared to $31 \%$ in Sweden, showed reactions from at least four different foods (18).

In our study, cow milk was the most common cause of allergy (32\%), followed by sweets and snacks containing a mixture of different foods such as; eggs, milk, chocolate, wheat, pepper and nuts. Meanwhile, the reaction to just eggs and nuts were reported only in 3 and 2 percent of children, respectively. Several studies showed that cow milk was the most common cause of food allergy $(6,11$, 13, 19). One study showed that in children with a history of asthma, allergic rhinitis and atopic dermatitis that underwent a skin prick test, a positive reaction to milk was reported in $21.7 \%$ of them, followed by eggs and wheat flour in $20 \%$ and $18.3 \%$ of children, respectively (20).

Another study in the east of Iran showed that the most frequent food allergen in atopic children was egg whites (17.8\%) (21). A study by Nasiri Kalmarsi et al. in the western parts of Iran showed by skin test that the reaction to fish, eggs, tomatoes, and cocoa was more common in children under 7 years of age (22). In one study in China, sea food, eggs and milk were common food allergens among children younger than 3 (5). Dr Pourpak et al. studied children with suspected food allergy and found that the most common food allergens were cow milk, tomato, egg white, egg yolk, beef and almond, in decreasing order of frequency (19). Another study in Seoul showed that eggs were the most frequent cause of reaction, followed by fruits, nuts, milk and crustaceans (16). Another investigation in allergic patients in Zanjan showed that wheat flour was the most frequent food allergen (23).

It seems that genetic and environmental factors, and even dietary habits in different societies can explain these differences and varied results. The lower report of reaction to eggs in our study might be explained by delay in adding of egg as complementary food, and also an early introduction to the consumption of snacks and sweets that usually contain eggs, thereby resulted that eggs not being considered as an important problem.

Our investigation showed that skin eruption including, dermatitis, urticaria and erthyrodermia, was the most common symptom, followed by GI, and then respiratory problems including dyspnea or cough. Ahanchian et al. that studied children with allergic symptoms and positive skin tests showed that asthma and allergic rhinitis were the most frequent manifestations of food allergy, followed by skin and GI involvement, respectively (21). Another study among under 10-year old children with food allergies showed that about $90 \%$ of the children had skin problems; systemic reactions, as well as GI and skin disorders were seen in $12 \%, 10 \%$ and $7 \%$ of children, respectively (24).

We found a significant correlation between cow milk allergy and wheezing GI and skin disorders were reported more frequently after candy consumption. A cohort study by Tariqe and colleagues demonstrated that egg allergy in infancy was associated with increased respiratory (asthma, rhinitis) allergic diseases (25). Sandin et al. found that cow milk allergy was more common among children with wheezing compared to children without wheezing (18).

In our study, there was a significant correlation between an age of less than 3 and the occurrence of reaction to foods. There were several studies with similar results (5, $8,13,16,21)$. However, some studies, did not show any correlation between age and food allergy $(6,24)$. This discrepancy might be caused by a difference in study design, sample size and the age range of the study group.

We didn't find any correlation between birth body weight, breast or formula feeding, time of starting complementary feeding and food reaction. Albeit, children with food reactions had a significantly lower duration of breast feeding. In a similar study in Korea, there was no relationship between birth weight, gestational age, type of delivery and food allergy. However, this correlation was significant with time and type of feeding in the first 6 months of life (24). Fletcher and his colleagues did not find any correlation between the duration of exclusive breastfeeding and food allergy (6). Several studies also confirmed that the amount and type of the mother's diet during pregnancy and lactation is more protective than exclusive breast feeding (26-29).

We didn't find any correlation between food reactions in males or females. Whilst it had significant correlation with family income. Several studies didn't show any difference in prevalence of reactions among boys and 
girls. But one cohort study illustrated the higher prevalence of reaction to peanut in boys $(4,24,30)$. Fleischer and colleagues demonstrated that maternal education and family income had a significant correlation with food allergy (6). Therefore, environmental factors might have an important role in the development of food allergy.

We found a significant correlation between food reactions and positive family history and personal history of atopy. Several investigations indicated similar results $(5,24,31)$. However, some studies didn't show this correlation $(6,30)$. Considering that IgE-mediated food reactions are common immunologic reactions to foods, thus its correlation with atopy could be desirable, nonetheless in some studies, non-IgE-mediated reactions might be considered as food allergies.

\section{Conclusion}

According to the results of this study, food reactions are a prevalent problem in children and after cow milk that was the most culprit food, snacks and sweats play an important role in the development of various skin, digestive and respiratory disorders. This study was based on parents' reports, therefore in addition to appropriate educational protocols for preventing, treating and resolving food problems in these children. The definite diagnosis and confirmation of culprit food by diagnostic tests including skin tests, serological tests and challenge tests could be useful.

\section{Acknowledgements}

This study was approved in the research committee of the Social Determinants of Health Research Center. We would like to thank the personnel of the daycare centers and the parents who helped us in the course of this study.

\section{Conflict of Interest}

Authors declare no conflict of interests.

\section{References}

1. Böhm 1- Boyce JA, Assa'ad A, Burks AW, et al. Guidelines for the diagnosis and management of food allergy in the United States: report of the NIAID-sponsored expert panel. J Allergy Clin Immunol. 2010; 126: S1-58. [DOI:10.1016/j.jaci.2010.10.007] [PMID] [PMCID]

2. Ahn K. The usefulness of component-resolved diagnostics in food allergy. Allergy Asthma Immunol Res. 2014; 6(2): 103-4. [DOI:10.4168/aair.2014.6.2.103] [PMID] [PMCID]

3. Dyer AA, Gupta R. Epidemiology of childhood food allergy. Pediatr Ann. 2013; 42(6): 91-5. [DOI:10.3928/0090448120130522-08] [PMID]

4. Branum AM, Lukacs SL. Food allergy among children in the United States. Pediatrics. 2009; 124(6): 1549-55. [DOI:10.1542/peds.2009-1210] [PMID]
5. Liu FL, Ning Y, Ma DF, et al. Prevalence of self-reported allergy, food hypersensitivity and food intolerance and their influencing factors in 0-36 months old infants in 8 cities in China. Zhonghua Er Ke Za Zhi. 2013; 51(11): 801-6.

6. Fleischer DM, Perry TT, Atkins D, et al. Allergic reactions to foods in preschool-aged children in a prospective observational food allergy study. Pediatrics. 2012; 130(1): e25-32. [DOI:10.1542/peds.2011-1762] [PMID] [PMCID]

7. Scurlock AM, Lee LA, Burks AW. Food allergy in children. Immunol Allergy Clin North Am. 2005; 25(2): 369-88. [DOI:10.1016/j.iac.2005.02.005] [PMID]

8. Chafen JJ, Newberry SJ, Riedl MA, et al. Diagnosing and managing common food allergies: a systematic review. JAMA. 2010; 303(18): 1848-56. [DOI:10.1001/jama.2010.582] [PMID]

9. Groetch M, Henry M, Feuling MB, Kim J. Guidance for the nutrition management of gastrointestinal allergy in pediatrics. J Allergy Clin Immunol Pract. 2013; 1(4): 323-31. [DOI:10.1016/i.jaip.2013.05.002] [PMID]

10. Guandalini S, Newland C. Differentiating food allergies from food intolerances. Curr Gastroenterol Rep. 2011; 13(5): 426-34. [DOI:10.1007/s11894-011-0215-7] [PMID]

11. Nowak-Wegrzyn A, Sampson HA. Adverse reactions to foods. Med Clin North Am. 2006; 90(1): 97-127. [DOI:10.1016/j.mena.2005.08.012] [PMID]

12. Mansoor DK, Sharma HP. Clinical presentations of food allergy. Pediatr Clin North Am. 2011; 58(2): 315-26. [DOI:10.1016/i.pcl.2011.02.008] [PMID]

13. Fiocchi A, Brozek J, Schünemann H, et al. World Allergy Organization (WAO) Diagnosis and Rationale for Action against Cow's Milk Allergy (DRACMA) Guidelines. World Allergy Organ J. 2010; 3(4): 57-161. [DOI:10.1097/WOX.0b013e3181defeb9] [PMID] [PMCID]

14. Berni Canani R, Di Costanzo M, Troncone R. The optimal diagnostic workup for children with suspected food allergy. Nutrition. $2011 ; \quad 27(10)$ : [DOI:10.1016/j.nut.2011.07.006] [PMID]

15. Lee SY. IgE mediated food allergy in Korean children: focused on plant food allergy. Asia Pac Allergy. 2013; 3(1): 15-22. [DOI:10.5415/apallergy.2013.3.1.15] [PMID] [PMCID]

16. Park M, Kim D, Ahn K, Kim J, Han Y. Prevalence of immediatetype food allergy in early childhood in seoul. Allergy Asthma Immunol Res. 2014; 6(2): $131-6$. [DOI:10.4168/aair.2014.6.2.131] [PMID] [PMCID]

17. Rona RJ, Keil T, Summers C, Gislason D, et al. The prevalence of food allergy: a meta-analysis. J Allergy Clin Immunol Pract. 2007; 120(3): 638-46. [DOI:10.1016/j.jaci.2007.05.026] [PMID]

18. Sandin A, Annus T, Björkstén B, et al. Prevalence of selfreported food allergy and $\mathrm{IgE}$ antibodies to food allergens in Swedish and Estonian schoolchildren. Eur J Clin Nutr. 2005; 59(3): 399-403. [DOI:10.1038/sj.ejcn.1602087] [PMID]

19. Pourpak Z, Farhoudi AH, Arshi S, et al. Common food allergens in children (a report from a referral center in tehran university of medical sciences). Acta Medica Iranica. 2004; 42: 40-5.

20. Hosseini S, Shoormasti RS, Akramian R, et al. Skin prick test reactivity to common aero and food allergens among children with allergy. Iran J Med Sci. 2014; 39(1): 29-35. 
21. Ahanchian H, Jafari S, Behmanesh F, et al. Epidemiological survey of pediatric food allergy in Mashhad in Northeast Iran. Electron Physician. 2016; 8(1): 1727-32. [DOI:10.19082/1727] [PMID] [PMCID]

22. Kalmarzi R, Ataee P, Homagostar G, Tagik M, Ghaderi E, Kooti W. Evaluation of the frequency of food allergens based on skin prick test in children in Kurdistan Province - Iran. Allergol Immunopathol. 2018; 46(1): 45-57. [DOI:10.1016/j.aller.2017.02.005] [PMID]

23. Ahmadiafshar A, Sepehri S, Moosavinasab SN, Torabi SZ. Recognition and frequency determination of common allergens in allergic patients of zanjan city by skin prick test. Zanjan Univ Med Sci J. 2008; 64(16): 45-54.

24. Kim NY, Kim GR, Kim JH, et al. Food allergen sensitization in young children with typical signs and symptoms of immediatetype food allergies: a comparison between monosensitized and polysensitized children. Korean J Pediatr. 2015; 58(9): 330-5. [DOI:10.3345/kjp.2015.58.9.330] [PMID] [PMCID]

25. Tariq SM, Matthews SM, Hakim EA, Arshad SH. Egg allergy in infancy predicts respiratory allergic disease by 4 years of age. Pediatr j Allergy Immunol. 2000; 11(3): 162-7. [DOI:10.1034/j.1399-3038.2000.00077.x]
26. de Silva D, Geromi M, Halken S, et al. Primary prevention of food allergy in children and adults: systematic review. Allergy. 2014; 69(5): 581-9. [DOI:10.1111/all.12334] [PMID]

27. Bunyavanich S, Rifas-Shiman SL, Platts-Mills TA, et al. Peanut, milk, and wheat intake during pregnancy is associated with reduced allergy and asthma in children. J Allergy Clin Immunol. 2014; 133(5): 1373-82. [DOI:10.1016/j.jaci.2013.11.040] [PMID] [PMCID]

28. Goldsmith AJ, Koplin JJ, Lowe AJ, et al. Formula and breast feeding in infant food allergy: A population-based study. J Paediatr Child Health. 2016; 52(4): 377-84. [DOI:10.1111/jpc.13109] [PMID]

29. Roduit C, Frei R, Depner M, et al. Increased food diversity in the first year of life is inversely associated with allergic diseases. J Allergy Clin Immunol. 2014; 133(4): 1056-64. [DOI:10.1016/j.jaci.2013.12.1044] [PMID]

30. Jung YH, Ko H, Kim HY, et al. Prevalence and risk factors of food allergy in preschool children in Seoul. Korean J Asthma Allergy Clin Immunol. 2011; 31(3): 177-83.

31. Brough HA, Simpson A, Makinson K, et al. Peanut allergy: effect of environmental peanut exposure in children with filaggrin loss-of-function mutations. J Allergy Clin Immunol. 2014; 134(4): 867-87. [DOI:10.1016/j.jaci.2014.08.011] [PMID] [PMCID]

\section{How to Cite This Article:}

Ahmadiafshar A, Mazloomzadeh S, Torabi Z, Haghighat K. An Epidemiological Survey of Food Reactions Among Kindergarten Children in Zanjan, Iran. J Adv Med Biomed Res. 2018; 26 (119) :6-11

\section{Download citation:

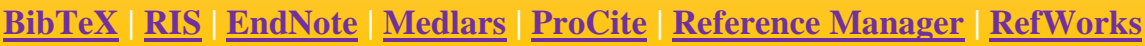

\section{Send citation to:}

8 Mendeley 2 Zotero (i) RefWorks $\underline{\text { RefWorks }}$ 